\title{
Metáforas en la gestión de servicios públicos ${ }^{1}$
}

Michael Barzelay*

\section{Introducción}

El modo de pensar convencional sobre "producción" en la Administración Pública está excesivamente centrado en la realización de tareas, sin conceder tanta atención a la mejora de procesos y la consecución de resultados. Este esquema no es casual. Puede ser explicado examinando como se desarrollaron las ideas sobre Administración Pública en los años cruciales de este siglo?.

\section{Negocios y producción como metáforas convencionales}

En los Estados Unidos, los reformistas de la Era Progresista ${ }^{3}$, incluído Woodrow Wilson, usaban ciertas metáforas para formular y expresar su concepción de la Administración pública. La metáfora crucial fue Government is a Business. Cuando uno lee los escritos de Wilson y otros reformadores, resulta fácil discernir un amplio abanico de traslaciones metafóricas que relacionaban empresa y Gobierno. Por ejemplo:

\begin{tabular}{|ll|}
\hline \multicolumn{1}{|c|}{ Empresa } & \multicolumn{1}{c|}{ Gobierno } \\
Empresa & Poder Ejecutivo \\
Consejero Delegado & Presidente \\
Búsqueda de beneficio & Servir los intereses públicos \\
Producción & Procedimientos y actividades admi \\
& nistrativas
\end{tabular}

Cuando la gente empieza a aceptar este tipo de imágenes, una metáfora como Government is a Business ejerce una gran influencia en cómo la gente percibe las cosas y cómo razona sobre ellas4. Piénsese por ejemplo en las poderosas implicaciones de otra metáfora convencional, "El tiempo es oro". Las metáforas proporcionan claves sobre cómo pensar acerca de conceptos abstractos y complejos, como son gobierno o tiempo. La traslación de Consejero Delegado a Presidente implica que el papel del Congreso es de control del ejecutivo, pero no dirección del mismo. La traslación de buisqueda de beneficio a servir los intereses públicos implica que el servicio público en sí mismo es la única recompensa para el Gobierno. De forma similar, la traslación de producción por procedimientos y actividades administrativas expresa que el Gobierno opera de forma eficiente si divide su funciones en tareas muy especializadas, asignando esos deberes a funcionarios bien preparados, los cuales deberán responder de su trabajo ante sus superiores. Si aceptamos que las metáforas operan de forma tan sistemática, potente y detallada como los científicos del conocimiento han demostrado recientemente, es evidente que la práctica del Gobierno ha estado profundamente influenciada por estas y otras traslaciones metafóricas.

Estas traslaciones o representaciones no se hicieron de forma casual. En buena parte fueron diseñadas por personas que deseaban una reforma en el modo de gobernar. Personas como Woodrow Wilson, gentes como las que componían los grupos de estudio de algunos municipios, o miembros de las comisiones de economía y eficiencia'. La influyente metáfora de Government is a Business fue especialmente bien recibida por aquéllos que aborrecían el spoils system 6 , o que no podian soportar hechos como funcionarios incompetentes, favoritismo en las contrataciones, laxitud en los controles financieros o mecanismos muy débiles de control de los organismos administrativos. En un momento en que los problemas de urbanización e industrialización del país eran muy importantes, la metáfora Government is a Business animaba a los ciudadanos a pensar en una, Administración pública como un instrumento técnico más, que bien organizado y gestionado podría convertir al Gobierno en un organismo capaz y eficiente para desarrollar las funciones públicas imprescindibles. Además, en la medida en que reformadores y burócratas pensaron en detalle en como lograr un Gobierno que funcionara de forma eficiente, se buscaron experiencias y estándares de buena gestión en el ámbito en el que se movían aquellas organizaciones que todos consideraban como las más productivas en el mundo: las grandes corporaciones industriales?. Como resultado de todo ello, la traslación producción a procedimientos y activida- 
des administrativas se fue construyendo de forma detallada y elaborada, de tal forma que lo que era cierto y aconsejable para las corporaciones industriales tenía plausiblemente que serlo también para las actividades gubernamentales. Gracias a este proceso, prácticas del tipo cobertura de vacantes basadas en la experiencia técnica de los candidatos, gran división del trabajo, programaciones de actividades, separación de los departamentos de ideas y producción, detalladas clasificaciones de puestos de trabajo, medición de las cargas de trabajo, o controles internos, se fueron convirtiendo en síntomas de una buena Administración Pública.

Estas prácticas y principios han conducido a las organizaciones públicas (así como a las privadas) a unos niveles de rendimiento que permiten mejoras potenciales significativas, a partir de recursos no explotados. Muchos de los atractivos de las ideas presentes en conceptos como "calidad total" o "reinvención del gobierno" deben ser relacionados con las concepciones que sobre estos temas mantienen los gestores públicos. Estamos siendo testigos, en buena parte, de un esfuerzo de revisión de las ya descritas representaciones metafóricas que conectaron el mundo de la empresa al entorno gubernamental. Probablemente no resulta exagerado afirmar que los ya citados proyectos de mejora de la gestión gubernamental reflejan, para bien y para mal, los ideales de la práctica empresarial del siglo $\mathrm{Xx}^{8}$.

Muchos gestores públicos encuentran cierta confusión ante el tipo de explicaciones que se usan para introducirlos en las nuevas corrientes de la gestión eficiente de servicios. Por ejemplo, algunos de los críticos de las prácticas convencionales alegan que los organismos gubernamentales prestan poca atención a los procesos. Al mismo tiempo, otros tantos alegan que la atención a los procesos es absolutamente excesiva. La verdad es que ambas partes tienen algo de razón. Una vía para disipar esta confusión es analizar el pasado y el presente en el uso de la metáfora Government is a Business.

Aquéllos que alegan que las organizaciones gubernamentales están poco orientadas a los procesos, de hecho se están haciendo eco de las actuales críticas a los principios y a las prácticas convencionales del mundo de la empresa. En ese contexto, el concepto de proceso está siendo puesto en relación con el de tarea y estructura. La principal proposición es que las corporaciones industriales han prestado una atención excesiva al control de las tareas que tenían que desarrollar sus trabajadores, dejando a un lado la mejora de los procesos a partir de los cuales se diseñan y se llevan a cabo sus productos. En relación a ello, el énfasis en los cometidos se refuerza estructurando las organizaciones en unidades funcionales responsables de aplicar habilidades y conocimientos a una categoría especíica de tareas y subprocesos. La observación de como se desarrollan las tareas en una red integrada de procesos clave, no acostumbra a dejarse en manos de los mismos que tienen que realizar la labor productiva. Problemas como baja calidad de los productos, altos costes de produción, o bajo desarrollo del producto se atribuyen a la falta de atención a los procesos relativos a tareas y estructura. Este tipo de críticas del mundo de la empresa, encuentra una buena acogida en la Administración Pública, como se pone de relieve en la proposición de realizar las cosas "mejor, más rápido y más barato", y en los esfuerzos para rediseñar procesos. Así, decir que la Administración presta poca atención a los procesos es afirmar que la metáfora Government is a Business necesita ser puesta al día.

Por el contrario, la afirmación de que los organismos gubernamentales prestan una atención excesiva a los procesos, pone de relieve los problemas creados por la forma en que los reformadores de inicios de siglo introdujeron la metáfora de la similitud entre Gobierno y empresa. Muchos de los conceptos, principios y prácticas del mundo empresarial fueron trasladados a las operaciones administrativas:

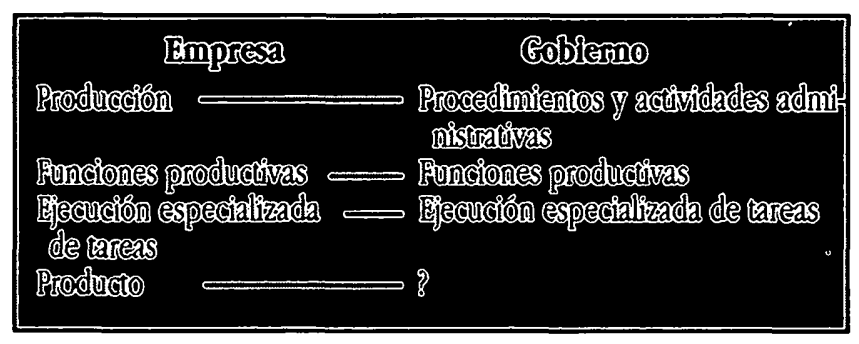

En parte, debido a que esta representación metafórica de la empresa al Gobierno resultaba incompleta en este aspecto crucial, reformadores y burócratas se acostumbraron a inferir que los organismos gubernamentales funcionaban correctamente si realizaban las tareas asignadas de forma coherente a las reglas fijadas por cada una de las distintas comunidades profesionales implicadas en dirigir y controlar los diferentes aspectos de las actividades de esos organismos. En el sector productivo, el hecho de que las empresas estuvieran implicadas en la realización de productos tangibles, con volúmenes y costes perfectamente computables, eliminaba la tendencia a derivaciones similares a las descritas para el ámbito gubernamental. Así, uno puede entender que la exigencia de una menor orientación al procedimiento es una forma de pedir que se tienda a evaluar más el rendimiento del Gobiemo a partir de la calidad, el coste y el volumen de los productos que realiza. Hacer al Gobiemo menos orientado al procedimiento (en este sentido) no sería una forma de poner al día la metáfora productiva repetidamente mencionada, sino una forma de profundizar en ella. 


\section{El servicio como metáfora}

\section{concurrente}

El problema es que insistir en la metáfora que correlaciona las actividades operacionales con la producción empresarial presenta serias limitaciones en muchos ámbitos de la actividad gubernamental. En muchos casos, los resultados de las actividades gubernamentales son típicamente intangibles. Por otra parte, para producirlos se requiere a menudo una cooperación significativa de los usuarios de los servicios gubernamentales, como la gente que se le pide que cumpla con ciertas regulaciones u otros requisitos. Como resultado de todo ello, el producto y los aspectos productivos de la metáfora mencionada no acaban de cuadrar excesivamente bien en el mundo de la Administración Pública.

Una metáfora mejor podría ser: "los procedimientos y actividades administrativas son como la prestación de servicios". Después de todo, productos intangibles y la coproducción con los usuarios son elementos clave en el mundo de los servicios y en el de la prestación de servicios, respectivamente. Debido a las grandes diferencias entre industria y servicios, por una parte, y entre industria y prestación de servicios, por otra, las teorías especializadas en gestión de servicios han evolucionado. De esas teorías de la gestión de servicios extraemos las siguientes representaciones o traslaciones:

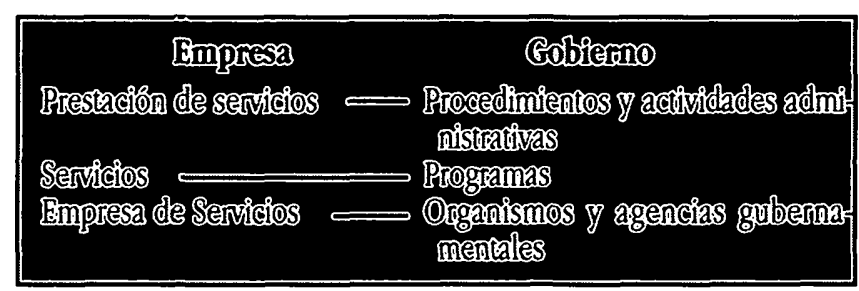

Es evidente que muchos de los términos usados en la prestación de servicios son frecuentemente usados en la Administración Pública. Pero ha de reconocerse que la concreción de esta traslación metafórica sólo está inicián- dose, sea en teoría o en la práctica (aunque esta generalización no tenga en cuenta casos como los de la Social Security Administrations' Old Age o el programa Survivors insurance, cuya orientación ai servicio es legendaria en los Estados Unidos). Las cosas podrían haber sido distintas si los ejemplos más sobresalientes de empresa en los inicios de este siglo hubieran sido empresas de servicios en vez de corporaciones industriales, o si los reformadores hubieran construido teorías específicas sobre la gestión estratégica de servicios. Sea como fuere, no podemos hacer volver la historia hacia atrás.

El uso de la metáfora que iguala las actividades operacionales de la Administración a la prestación de servicios del mundo privado, puede proporcionar apuntes e ideas sistemáticas acerca de la mejora de las actividades gubernamentales. Es fácil imaginar el porqué. Esas ideas pueden usarse como palanca de mejora de las prácticas que se han ido construyendo sobre la histórica metáfora de actividadadministrativa-como-producción (aunque sin producto). Y las relativas similaridades entre actividades operacionales en el Gobierno y las características de la prestación de servicios, sugiere que elaborando y aplicando la metáfora del servicio puede resultar más útil que la simple adaptación de la metáfora productivą. Además, todos somos buenos conocedores de la prestación de servicios, ya que diariamente ejercemos de ciudadanos-consumidores.

En general, podemos afirmar que la comprensión de la gestión estratégica de servicios puede ayudar a formular una lista sistemática y detallada de cuestiones prácticas sobre como gestionar los programas gubernamentales. Cuanto más se acerque una actividad administrativa a la prestación de servicios y menos a la producción de bienes, más útil será la ventaja comparativa de usar la metáfora de los servicios para entender la situación, para estimular el pensamiento creativo y para ir comprobando su aplicabilidad en la gestión de actividades administrativas. En definitiva, así como la mejor prueba para conocer la calidad de un pastel es probarlo, la demostración sobre la utilidad de esta propuesta reside en comprobar si su aplicación consigue mejorar la capacidad de conocer y de actuar de los organismos y agencias gubernamentales.
Articulo traducido por Joan Subirats Humet.

- Kennedy School of Government. Universidad de Harvard.

' Estas notas surgieron de un trabajo, aún en curso, que se realiza con el profesor Georges Lakoff de la Universidad de California, Berkeley

2 Ver Michael Barzelay: Breaking Through Bureaucracy. A New Vision for Managing in Government, Berkeley, University of California Press, capitulos 1 y 8 .
${ }^{3}$ El autor se refiere a un conjunto de personas que se han denominado genéricamente como "reformadores", más por compartir un mismo cuadro de valores y propuestas, que por su carácter organizado. Se desarrolló su labor a finales del siglo xIx, principios del $\mathrm{xx}$, coincidiendo con un proceso de rápida industrialización y urbanización de Estados Unidos. Sus posiciones descansaban esencialmente en su convicción del papel benéfico de la ciencia en los problemas públicos, postulando una mayor tecnificación y mora- 
lización de la vida pública, y un menor peso de la política entendida como actividad exclusivamente partidista y clientelar (nota del traductor).

- Ver George LaKoff y Mark Johnson: Metaphors We Live By, Chicago, University of Chicago Press, 1980.

s Ver al respecto el contenido de la nota 3 (nota del traductor).

${ }^{6}$ Como es bien sabido, el autor se refiere a un sistema de provisión de puestos en la Administración vigente en Estados Unidos hasta principios del siglo $\mathrm{xx}$, cuya premisa fundamental era la vinculación políica y clientelar del personal al servicio de las diversas Administraciones con el político que temporalmente ocupaba el poder en esa Administración.

7 Reformadores y burócratas examinaron tanto los ejemplos de las grandes corporaciones industriales como aquellos otros idealizados por los teóricos de "management" científico.
- Véanse las críticas a esta tendencia en Donald J. Savole: Thatcher, Reagan, Mulroney: In Search of a New Bureaucracy, Pittsburgh, University of Pittsburgh Press, 1994, y Christopher Pourt: Managerialism and the Public Services, 2 edic. Oxford, Blackwell, 1993 (existe traducción espanola en Instituto de Estudios Fiscales, Madrid, 1993).

- Debería subrayarse que en los últimos años muchas ideas de la gestión estratégica de servicios han ido siendo aplicadas en las corporaciones industriales, como, por ejemplo, la idea de los clientes internos a la propia empresa. Además, las teorias de la gestión estratégica de servicios han ido retomando muchas ideas del sector productivo, como el marketing o el control de procesos. En definitiva, existe un considerable solapamiento entre las teorías de la gestión estratégica de servicios y las teorías contemporáneas acerca de cómo mejorar el rendimiento de las corporaciones industriales. Pero ese solapamiento no es en absoluto total. 